\title{
Tailings dewatering by pressure filtration: process optimisation and design criteria
}

\author{
F Kaswalder Aqseptence Group Srl, Italy \\ D Cavalli Aqseptence Group Srl, Italy
}

A Hawkey Diemme Filtration, Australia

A Paglianti University of Bologna, Italy

\begin{abstract}
Tailings dry stacking is a mine tailings storage method that presents many advantages and is becoming increasingly attractive to the mining industry. Filter presses are able to reach very high performance in terms of cake dryness. However, thorough process testing and analysis is critical in order to determine the ideal equipment selection and sizing. This approach will result in the most desirable performance versus cost outcome. To achieve this, a comprehensive study of each case should be conducted by means of target definition, characterisation of the material (with different physico-chemical analytical techniques) laboratory-scale filtration tests and, if deemed necessary, pilot-scale campaigns. In the present work, a series of case studies are presented showing how these different steps contribute to the design and customisation of the filter presses and describing their main features.
\end{abstract}

Keywords: filter press, cake filtration, dry stack disposal, slurry characterisation

\section{Introduction}

Generally speaking, mine tailings can be considered as cake (or filtered tailings) when they don't show any liquid behaviour due to a dewatering process. Following this definition, mine residue suspensions (a solids and water mixture) can be considered as cakes if their strength (e.g. static yield stress) overcomes the liquid limit (typically $2 \mathrm{kPa}$ ), as shown in Figure 1 (Jewell and Fourie 2015).

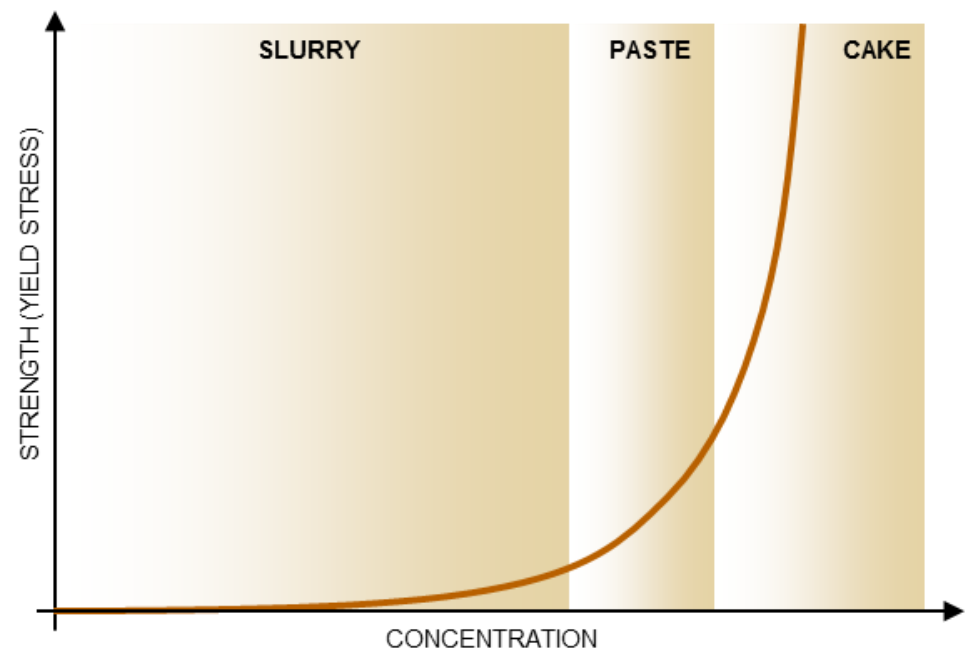

Figure 1 Classification of tailings residues in terms of strength of the suspension

In contrast to conventional thickened or paste tailings, filtered cakes are suitable for transportation by conveying or trucking, and furthermore for stacking and compaction to meet the geotechnical constraints for tailings storage in perpetuity, the so-called dry stacking. 
This storage method presents a series of advantages, e.g.:

1. Reduction of the environmental impact of traditional dams (failures, leaks).

2. Reduced footprint of the residue handling facility (higher compaction and increased heights).

3. The filter cakes can be stacked on the land previously used for wet storage and evaporation.

4. Filtrate recovery, when the liquid phase contains valuable products (e.g. soda in the Bayer process or cyanide complexes in gold/silver extraction) including water (in fact, water conservation is often an important driver).

Dry stacking (Figure 2) can represent in many cases the only viable solution for tailings management. For example, when fresh water is limited (arid locations), its recovery from a conventional tailings dam is impossible (severely cold climate) or, in case of severely wet climates, comes with an associated high risk of dam failure.

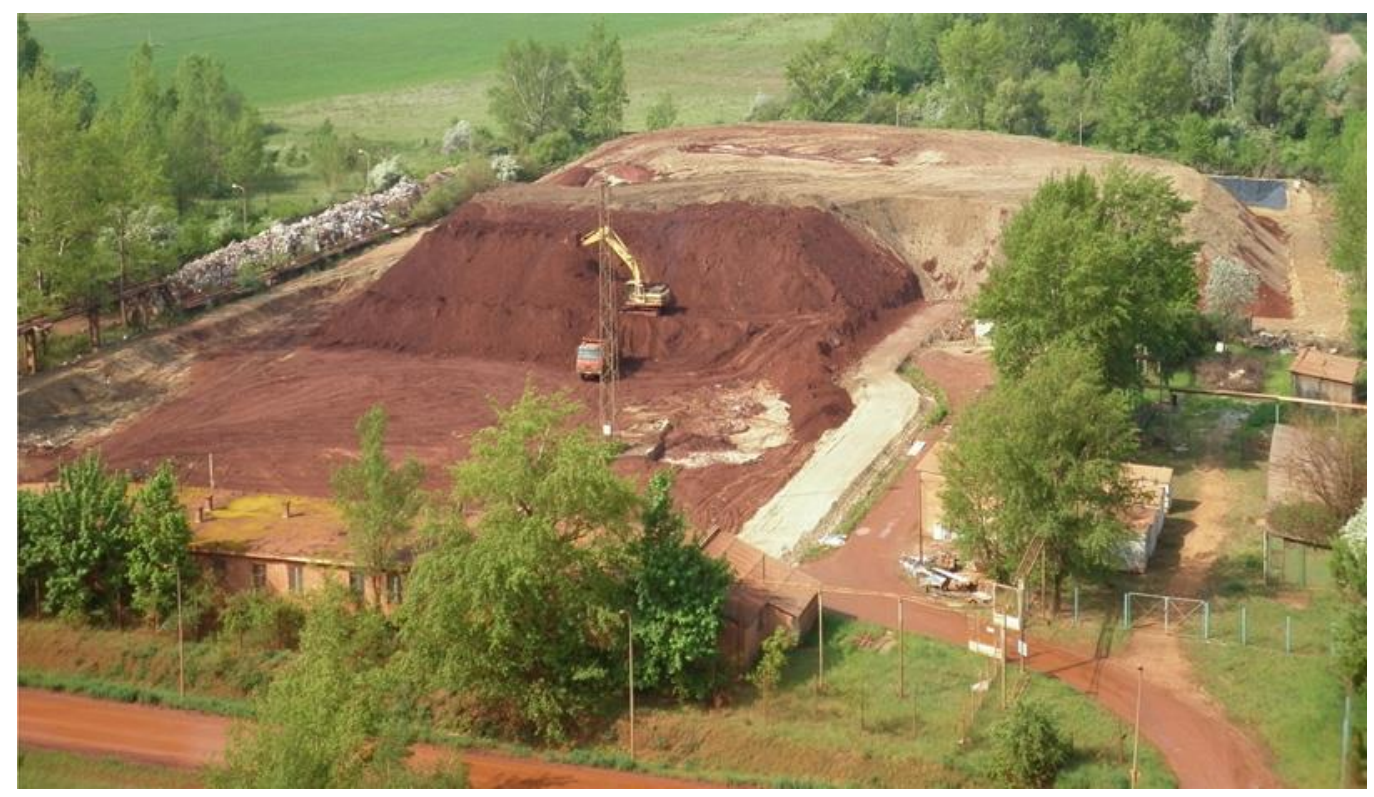

Figure 2 Example of cake dry stacking

A partially saturated cake can be obtained by means of different devices. The most established of these are vacuum filters, belt filters, hyperbaric filters and filter presses.

Compared to other technologies (e.g. vacuum and hyperbaric), filter press filtration provides the ability to obtain very high dewatering levels, producing dewatered tailings cakes with residual moisture values as low as $15-20 \% \mathrm{w} / \mathrm{w}$, which are compact and perfectly transportable and stackable. This represents an important step forward and has led to a significant increase of the number of plants that have been using filter press technology during recent years.

The filter press is a fully customisable machine that can be adapted to the requirements of the customer. The cake dewatering process in a filter press is quite complex and can include a series of steps, such as consolidation by membrane squeezing, desaturation by air blowing, and deliquoring. Each step should be optimised and properly set-up (Stickland et al. 2016, 2017).

This versatility makes the filter press design and sizing phase critical. In fact, the technology and all the process variables are defined on the basis of the targets to be achieved. The result is a customised dewatering technology able to provide the required results at the lowest cost.

Therefore, from this point of view, careful attention must be drawn to the testing and piloting phases, which precede the elaboration of the commercial proposal and start from the study and characterisation of the product to be treated, to the filtration tests which are aimed at defining the process parameters. 
To do this, the testing phase is very important in order to define the process parameters and the conditions that are necessary to achieve the requested dehydration performances. The chemical and physical characterisation of the product is very important during this phase as well, since it will form an important reference for the performance guarantee.

The characteristics that are generally analysed in the mineral industrial tailings are the following:

1. Solids content.

2. Specific weight.

3. Particle size distribution.

4. Liquor characteristics (conductivity, $\mathrm{pH}$, density, TDS, etc.).

These parameters allow one to have a general idea of the tailings filterability.

However, the product is often a very complex matrix, especially for its solids composition, and even the smallest variation can be crucial in the achieving of the requested target in that particular process condition.

This is the reason why the Aqseptence Group Filtration and Thickening Systems (Diemme Filtration) research and development department is equipped to perform a characterisation that could be the most accurate and thorough possible, in order to get a deep insight into the treated matter. As for the tailings coming from the mineral industry, their mainly inorganic composition requires the application of some X-ray spectroscopy fluorescence (XRF) and diffraction (XRD) techniques in order to qualify and quantify the elemental and phase composition, respectively (Kaswalder et al. 2014).

The optimisation of the mine tailings dewatering process is often challenging, and tailings behaviour in terms of filterability cannot be explained just by looking at one parameter. An example is shown in Figure 3, where the efficiency of air blowing (lowering of cake moisture) is related to a coefficient defined as the mean diameter D[4,3] multiplied by the content of non-phyllosilicates.

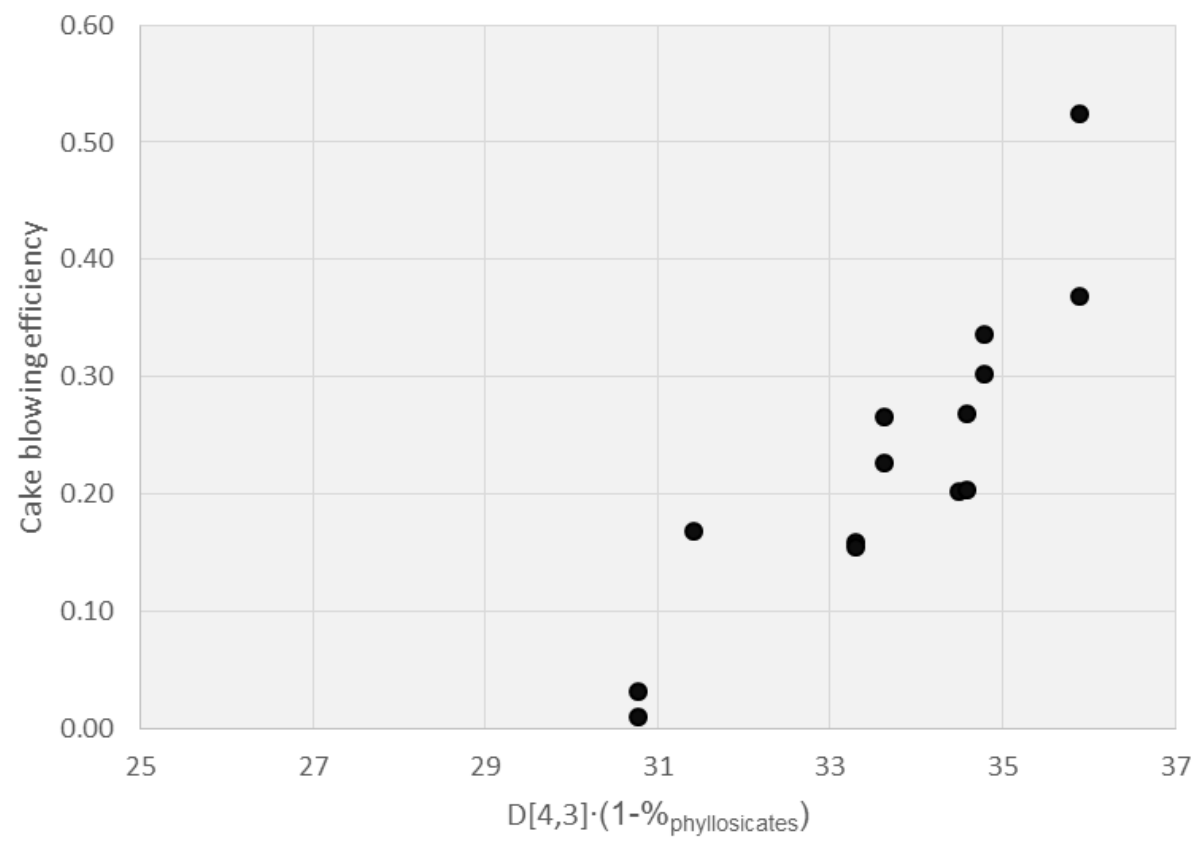

Figure 3 Cake blowing (desaturation) efficiency related to $D[4,3]$ and phyllosilicates content 
To get all the process data necessary for the sizing of the filter press, a test campaign is mandatory. To do this, Diemme Filtration is equipped with pilot filters of different scale.

The bench scale rig is shown in Figure 4.

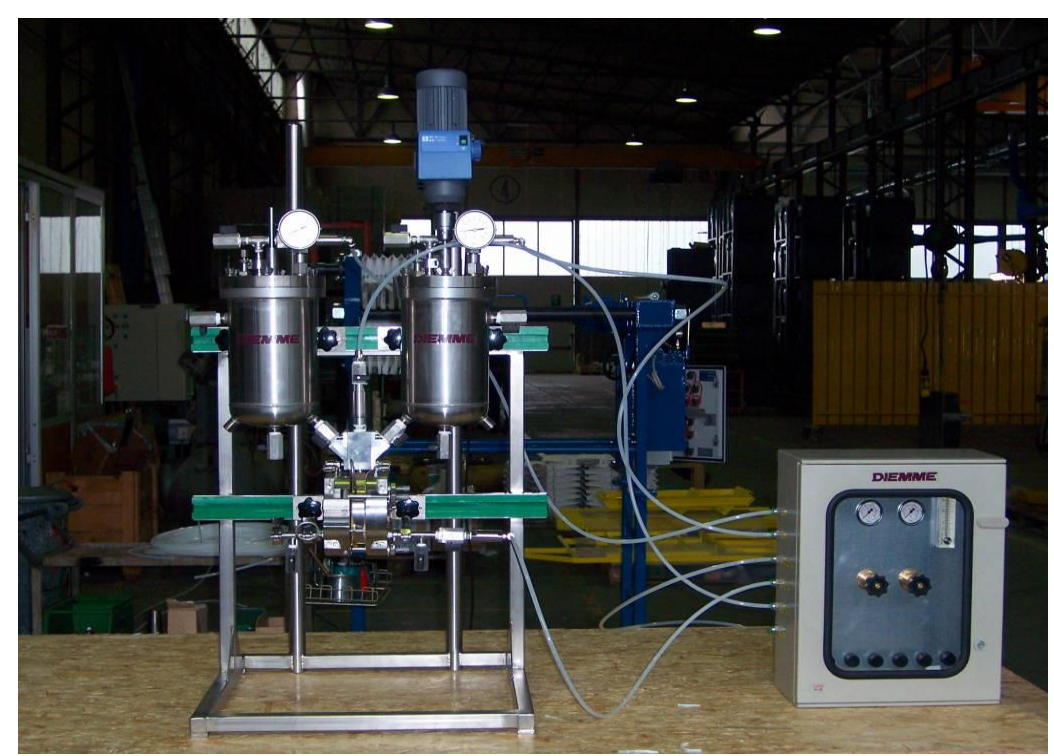

Figure 4 Bench scale filter rig

Some data about the filter rig are listed below:

- Slurry/washing fluid tank capacity: 3.5 litres.

- Chambers volumes: 0.1-0.5 litres (depending on chamber thickness).

- Construction material: stainless steel (titanium version also available).

- Feed pressure: 1-15 bar.

- Squeezing pressure: 1-40 bar.

The unit permits the simulation of the formation of a single cake, feeding the filtration chamber from a tank with compressed air in order to simulate the pump's working pressure. It is equipped to reproduce all the possible process configurations of an industrial filter press with variation of a series of parameters such as:

1. Chamber thickness.

2. Chamber type (with fixed or variable volume, with membrane).

3. Working pressures (feeding, squeezing, blowing).

4. Simulation of the consolidation phases (membrane squeezing), desaturation (cake blowing), deliquoring (cake washing).

The obtained results are perfectly scalable and the industrial equipment can be sized based on these.

If larger-scale onsite test sessions are required, pilot filter stations with different features (such as filter capacity, plate design, etc.) are available (Figure 5). These are often used to produce sufficient amounts of filter cake for geotechnical testing (typically hundreds of kilograms). 


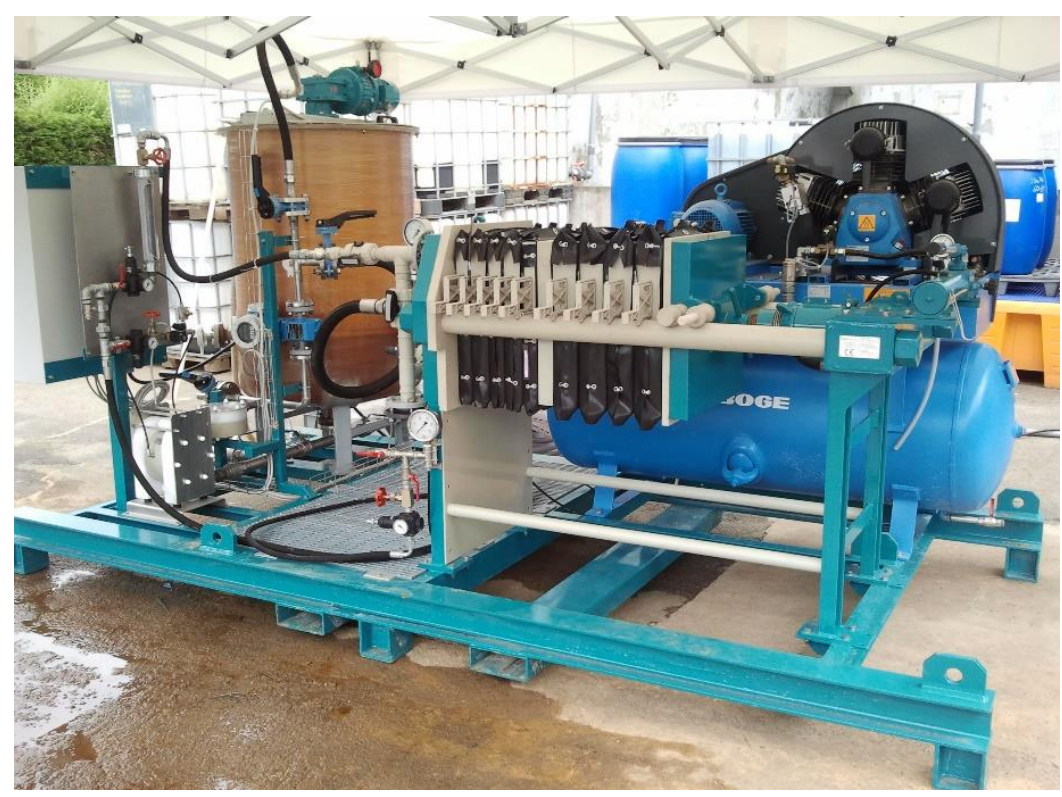

Figure 5 Large-scale pilot filter

In the following section a series of case studies are described, highlighting that mine tailings, despite a series of analogies, have substantial differences which determine different filtration behaviour, but are not obvious without comprehensive study. In view of this, different pressure filtration technologies (filter press configurations) must be used for the treatment of these products.

\section{$2 \quad$ Case studies}

\section{$2.1 \quad$ Nickel laterite tailings}

Nickel laterite tailings present a series of analogies with bauxite residue tailings, which was previously (only a few years ago) assumed to be difficult to filter and stack, but now filtration and dry stacking has become the preferred residue management method. In Figure 6 , an installation of Diemme Filtration filter presses for bauxite residue dry stack disposal is shown (see Section 2.4 for further details).

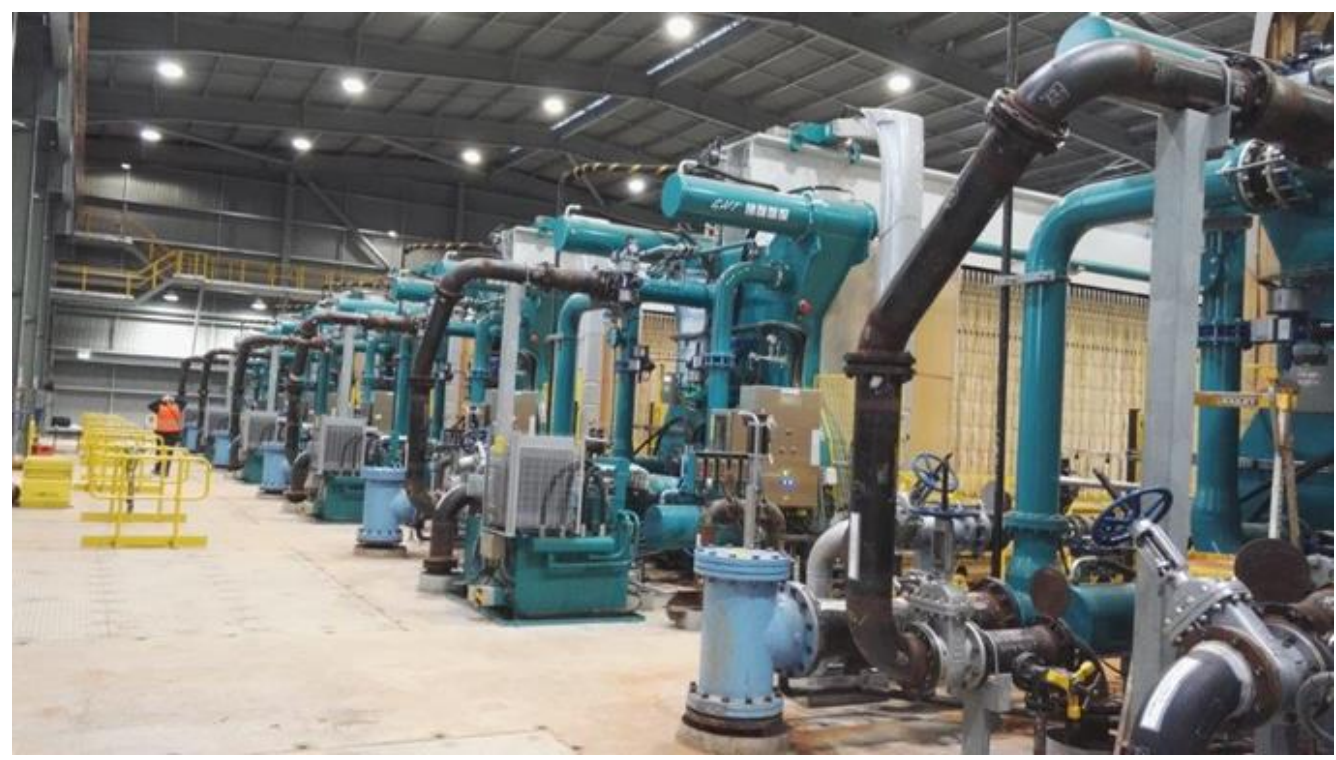

Figure 6 Bauxite residue dry stack facility 
In Tables 1 and 2, a comparison in terms of elemental composition and particle size distribution between different kinds of bauxite residues (BR) and nickel laterite tailings (NLT) are shown. It can be noted that the particle size distributions of bauxite residues are far finer than those of nickel laterite residues. This would indicate (and has now been proven) that nickel laterite residues should be no harder to dewater than bauxite residues.

Table 1 Elemental composition (values are reported as $\% \mathrm{w} / \mathrm{w}$ )

\begin{tabular}{llllllll}
\hline Case study & $\mathrm{Fe}_{2} \mathrm{O}_{3}$ & $\mathrm{Al}_{2} \mathrm{O}_{3}$ & $\mathrm{SiO}_{2}$ & $\mathrm{CaO}$ & $\mathrm{TiO}_{2}$ & $\mathrm{Na}_{2} \mathrm{O}$ & $\mathrm{MgO}$ \\
\hline BR1 & 33 & 29 & 21 & 2 & 5 & 0 & 0 \\
$\mathrm{BR} 2$ & 32 & 26 & 12 & 3 & 14 & 11 & 0 \\
$\mathrm{NLT} 1$ & 25 & 2 & 28 & 10 & 28 & 2 & 2 \\
$\mathrm{NLT2}$ & 42 & 3 & 4 & 10 & 19 & 0 & 0 \\
\hline
\end{tabular}

Table 2 Particle size distribution

\begin{tabular}{llllll}
\hline Case study & $\mathbf{P}_{100}$ & $\mathbf{P}_{80}$ & $\mathbf{P}_{50}$ & $\mathbf{P}_{20}$ & $\mathbf{P}_{10}$ \\
\hline BR1 & $<500 \mu \mathrm{m}$ & $<10 \mu \mathrm{m}$ & $<3 \mu \mathrm{m}$ & $<0.3 \mu \mathrm{m}$ & $<0.2 \mu \mathrm{m}$ \\
BR2 & $<250 \mu \mathrm{m}$ & $<16 \mu \mathrm{m}$ & $<2 \mu \mathrm{m}$ & $<1.6 \mu \mathrm{m}$ & $<0.3 \mu \mathrm{m}$ \\
NLT1 & $<230 \mu \mathrm{m}$ & $<35 \mu \mathrm{m}$ & $<5 \mu \mathrm{m}$ & $<0.7 \mu \mathrm{m}$ & $<0.3 \mu \mathrm{m}$ \\
NLT2 & $<800 \mu \mathrm{m}$ & $<12 \mu \mathrm{m}$ & $<5 \mu \mathrm{m}$ & $<1.6 \mu \mathrm{m}$ & $<0.8 \mu \mathrm{m}$ \\
\hline
\end{tabular}

The filtration test confirmed this trend, showing similar results as reported in Table 3.

Table 3 Cake moisture content and filter cycle time of pressure filtered BR and NLT residues

\begin{tabular}{lllll}
\hline Case study & $\begin{array}{l}\text { Feed } \\
\text { concentration } \\
(\% \mathbf{w} / \mathbf{w})\end{array}$ & $\begin{array}{l}\text { Cake moisture } \\
\text { content } \\
(\% \mathbf{w} / \mathbf{w})\end{array}$ & $\begin{array}{l}\text { Cake } \\
\text { density } \\
\text { (kg/L) }\end{array}$ & $\begin{array}{l}\text { Pressure } \\
\text { filter cycle } \\
\text { time (min.) }\end{array}$ \\
\hline BR1 & 41.4 & 25 & 1.90 & 20 \\
BR2 & 43.5 & 24 & 2.00 & 20 \\
NLT1 & 39.6 & 31 & 1.70 & 15 \\
NLT2 & 43.7 & 25 & 2.10 & 15 \\
\hline
\end{tabular}

\subsection{Kupol gold mine - Chukotka, Russia}

The remote Kupol gold mine (Figures 7 and 8 ) is located within the Arctic Circle in the far eastern region of Siberia. It is only accessible by air or, during the coldest months, by a temporary ice road. A dry stacking operation using filter presses was considered a favourable tailings management solution when compared with the option of extending or duplicating the existing tailings dam. One of the important advantages of a dry stacking solution is that more consistent and efficient water recovery from the tailings dam is possible in very cold climates. Not only did the technology offer better performance, it was more economic when taking the climate and other environmental factors into account. 

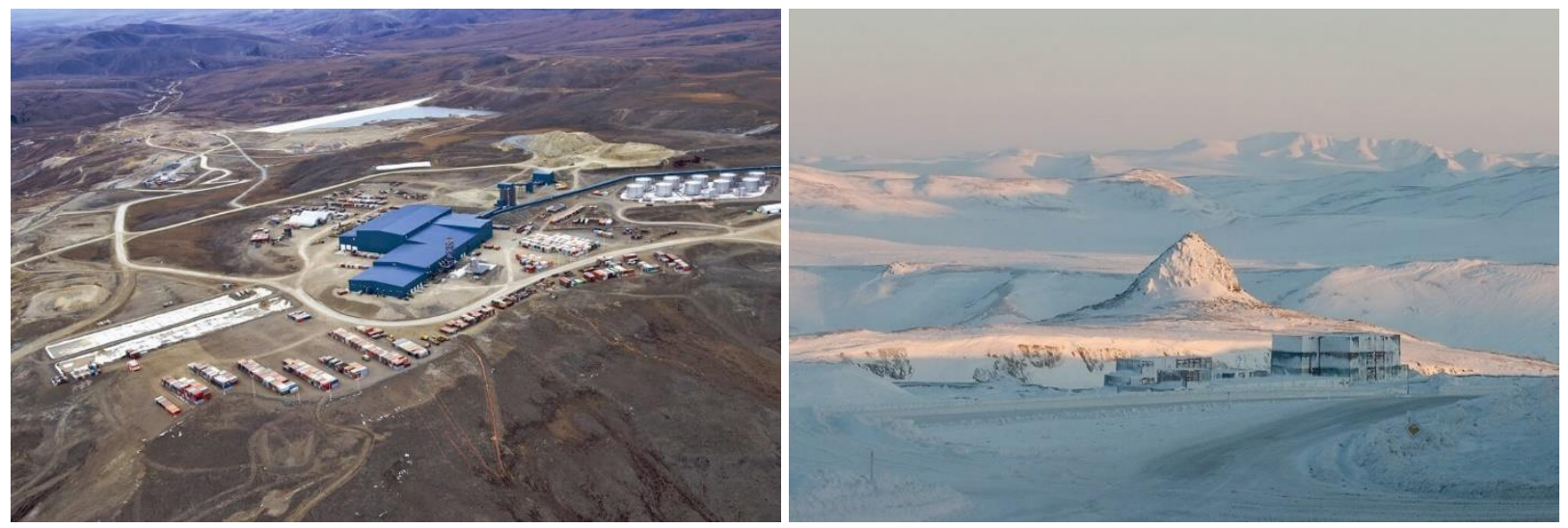

Figure 7 Aerial views of the installation
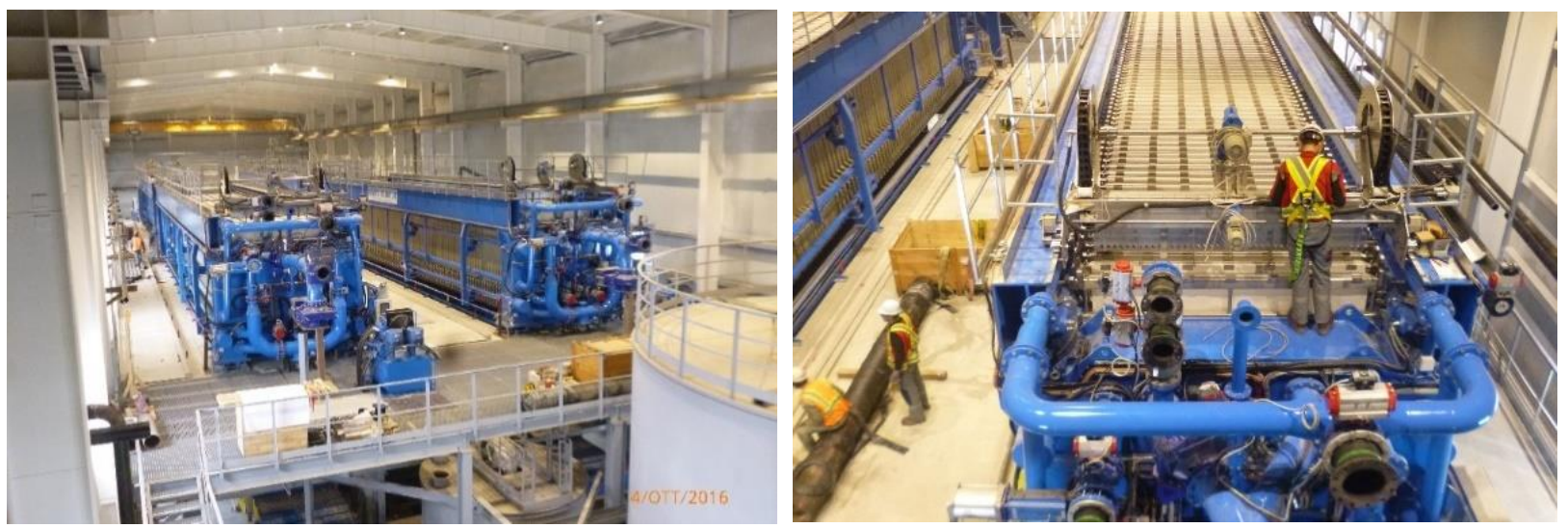

Figure 8 Filter presses installed at Kupol gold mine

Another advantage of the dry stacking option was time. The dry stacking plant using filter presses offered the shortest delivery time. Delivery of the equipment required precise coordination with the limited access period afforded by the ice road.

In this case, the tailings consists of a thickened slurry with a solids fraction mainly composed of quartz. The particle size distribution (PSD) curve (Figure 9) shows a polydisperse distribution with a significant coarse population (see peak around 100 micron).

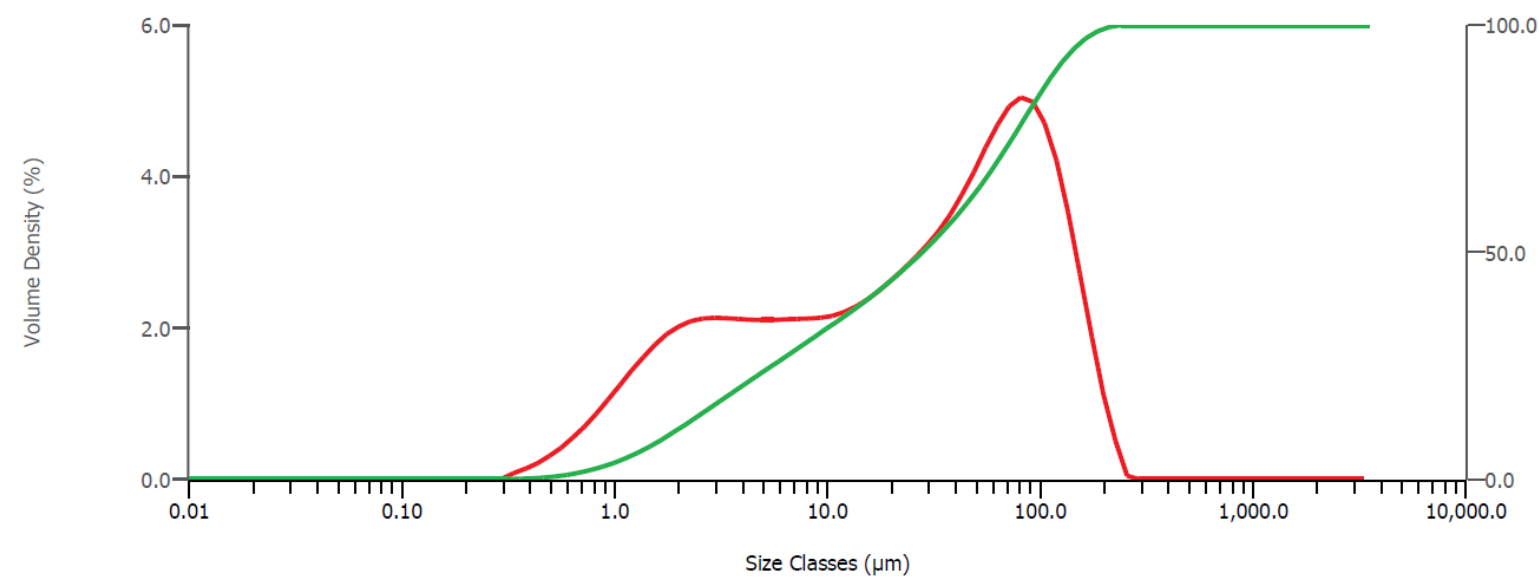

Figure 9 Kupol gold mine tailings PSD 
These features have been taken into account in the design of the filters, considering that a solids fraction with this size distribution can produce tixotropic cakes that should be desaturated by air blowing. Even if there was no evidence of cake tixotropicity or stickiness during the test campaign, the filters have been designed to do the cake blowing, assuming that few changes in the PSD can drastically change the cake features. This consideration was supported by the mineralogical analysis that shows quartz and feldspar as predominant phases, with only a little amount of phyllosilicates. In these cases, tailings often show a tendency to form tixotropic cakes.

Filter specifications:

- Filters installed: $4 \times$ GHT2500.F20.

- Filtration area: $830 \mathrm{~m}^{2}$ each.

- Cake volume per cycle: $16 \mathrm{~m}^{3}$.

- Plate pack: variable volume chambers (mixed plate pack).

- Cake thickness: $40 \mathrm{~mm}$ (before squeezing).

- Number of plates: 91 plates per filter.

- Filter designed for cake blowing.

- Cloth rinsing system (after cake discharge on each filtration cycle).

- High-pressure cloth washing system (initiated periodically).

Process conditions:

- Duty (suspended solids): $225 \mathrm{t} / \mathrm{hr}$.

- Cycle time: 16 minutes.

- Cake density (in chamber): $2 \mathrm{~kg} / \mathrm{L}$.

- Cake bulk density (after discharge): $1.5 \mathrm{t} / \mathrm{m}^{3}$.

- Final cake moisture content: $15 \% \mathrm{w} / \mathrm{w}$.

- Feed suspended solids concentration: $45 \% \mathrm{w} / \mathrm{w}$.

- Filter cake production: $132 \mathrm{~m}^{3} / \mathrm{hr}$.

\subsection{Gold tailings dewatering and washing facility - Mexico, counter-current decanting thickener replacement}

The Real del Monte operation in Pachuca, Mexico uses the Merrill Crowe process to extract gold and silver. The filter presses installed at this facility not only dewater the tailings but also wash the filter cake in the filter to recover cyanide and valuable product. Conventionally, in Merrill Crowe plants, the cyanide and product recovery is achieved using counter-current decanting thickeners (CCDs). There are significant advantages in using filter presses instead of CCDs. The cyanide, gold and silver recovery is much higher and the wash water consumption is much lower due to the excellent washing efficiency of the filters. Even replacing existing CCDs with filter presses (Figure 10) in this situation is usually very economical because of the increased recovery of gold and silver. 

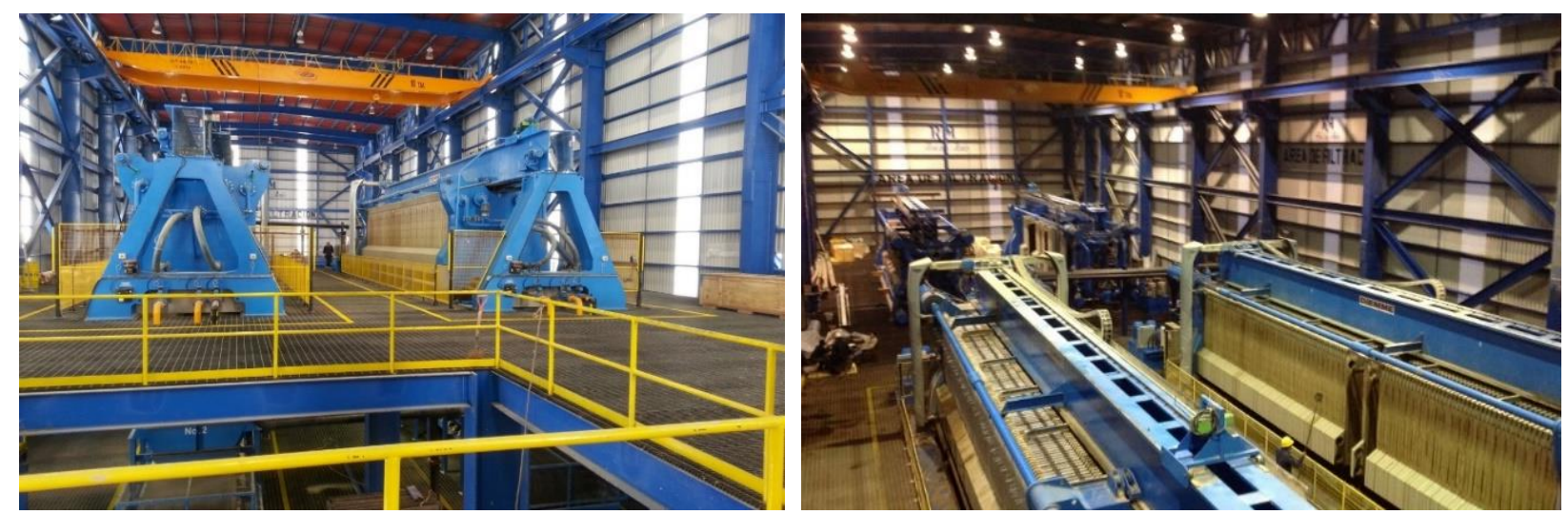

Figure 10 Installation of the filter presses

The washing efficiency has been proven during a test campaign focused on the deliquoring step. The process parameters have been properly tuned considering that, due to the presence of a relevant fine fraction, inhomogeneous distribution of the washing liquid into the chamber could be a major issue.

As shown in Figure 11, an efficiency close to $100 \%$ precious metal recovery can be achieved with less water demand compared to the CCD system.

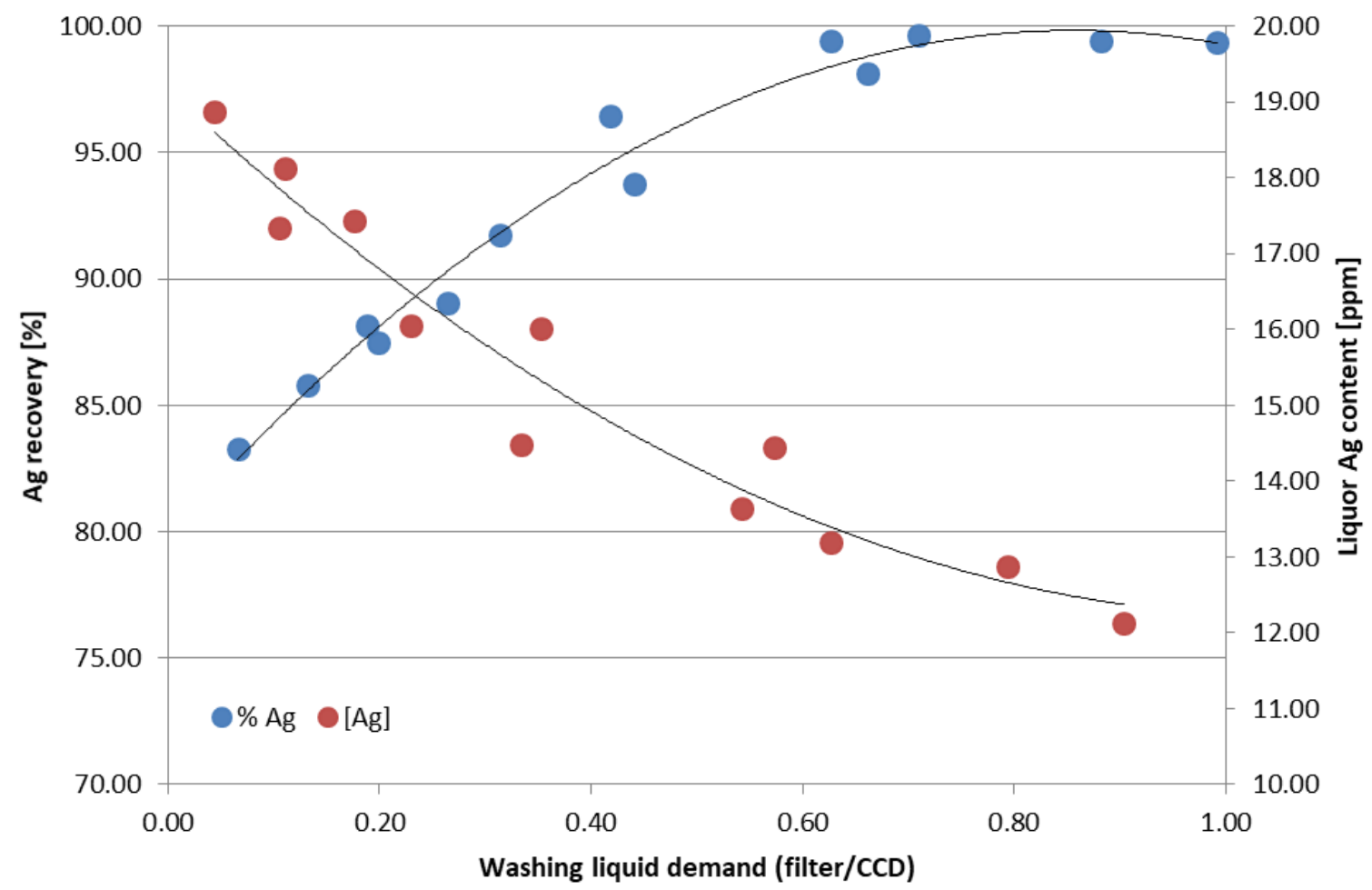

Figure 11 Silver $(\mathrm{Ag})$ recovery into the filter press

Filter specifications:

- Filters installed: $4 \times$ GHT2500.P12.

- Filtration area: $1,150 \mathrm{~m}^{2}$ each.

- Cake volume per cycle: $30 \mathrm{~m}^{3}$.

- Plate pack: variable volume chambers (mixed plate pack).

- Cake thickness: $40 \mathrm{~mm}$ (before squeezing). 
- Number of plates: 121 plates per filter.

- Filter designed for cake washing and blowing.

- High-pressure cloth washing system (initiated periodically).

Process conditions:

- Cycle time: 45 minutes.

- Cake density (in chamber): $2.1 \mathrm{~kg} / \mathrm{L}$.

- Cake bulk density (after discharge): $1.5 \mathrm{t} / \mathrm{m}^{3}$.

- Final cake moisture content: $15 \% \mathrm{w} / \mathrm{w}$.

- Feed suspended solids concentration: $35 \% \mathrm{w} / \mathrm{w}$.

- Cake washing efficiency: $99.5 \%$.

- First-stage cake wash solvent: barren liquor.

- Second-stage cake wash solvent (optional): process water.

\subsection{Bauxite residue dewatering and stacking - alumina refinery, Western Australia}

The existing wet bauxite residue storage facility at an alumina refinery in Western Australia (Figure 12) was approaching its capacity and extending this facility was considered highly problematic, if not impossible. The land around the refinery and residue area is transitioning from industrial to residential use and the consequences of this include higher land costs and increasing public health and safety concerns. The option to dewater the residue in filter presses and stack the dry cake on top of the existing storage area was very attractive to the client and provided additional advantages, including increased water recovery.
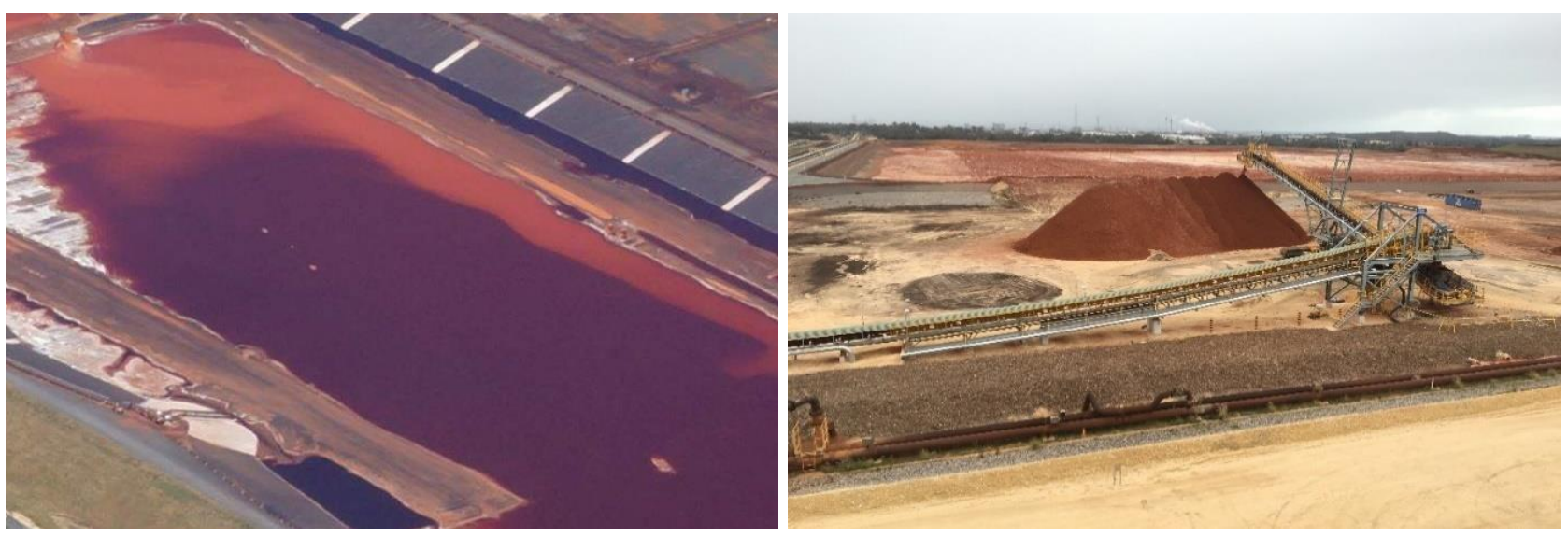

Figure 12 Dam and dry stack facility

After selecting pressure filtration (using plate filter presses) as the preferred dewatering method, the client conducted a very long and detailed study to determine the most appropriate filter presses (and optimum configuration) for the bauxite residue dewatering facility. For the project to be economical, very large filter presses were required (in fact, larger than installed anywhere previously) in order to minimise the number of equipment trains (each train comprising feed pump, filter press, cake discharge feeder and other ancillaries). The configuration of the filter press plate pack used here is important in that it keeps the filters as simple as possible (fixed-volume chamber). The particle size distribution of this particular residue material allows good cake formation (and a cake moisture result under the target) under feed pump pressure alone, without the requirement of membranes or diaphragms to provide additional cake squeezing. 
Filter specifications:

- Filters installed: 6 × GHT2500.P18.

- Filtration area: $1,750 \mathrm{~m}^{2}$ each.

- Cake volume per cycle: $30 \mathrm{~m}^{3}$.

- Plate pack: fixed-volume chambers.

- Cake thickness: $35 \mathrm{~mm}$.

- Number of plates: 184 plates per filter.

- High-pressure cloth washing system (initiated periodically).

Process conditions:

- Duty (suspended solids): $250 \mathrm{t} / \mathrm{hr}$.

- Cycle time: 30 minutes.

- Cake density (in chamber): 2 kg/L.

- Cake bulk density (after discharge): $1.5 \mathrm{t} / \mathrm{m}^{3}$.

- Final cake moisture content: $30 \% \mathrm{w} / \mathrm{w}$.

- Feed suspended solids concentration: $40 \% \mathrm{w} / \mathrm{w}$.

- Filter cake production: $179 \mathrm{~m}^{3} / \mathrm{hr}$.

\section{Conclusion}

Dry stacking of mine tailings dewatered using pressure filtration is now very popular around the world in situations where conventional tailings dams are difficult (or expensive) to build and maintain, or where water is scarce and needs to be recovered from the tailings slurry efficiently. The process can be enhanced to include in-filter cake washing to recover valuable products or remove contaminants harmful to the environment. The range of mineral tailings to which this technology has been applied is now very extensive. Dewatering by pressure filtration followed by dry stacking has become the default tailings management solution for bauxite residue, one of the more challenging mineral tailings materials. There is no reason why the same techniques cannot be applied to nickel laterite tailings and other laterite residues previously thought to be difficult to dewater, because on closer examination, these materials should behave at least as favourably as bauxite residue.

\section{References}

Jewell, RJ \& Fourie, AB (eds) 2015, Paste and Thickened tailings - A Guide, 3rd edn, Australian Centre for Geomechanics, Perth, pp. 287-304.

Kaswalder, F, Collini, D, Masciocchi, N \& Guagliardi, A 2014, 'X-ray techniques: a new vision for the field of wastewater filtration', Filtration+Separation, vol. 51, no. 6, pp. 36-39.

Stickland, AD, Irvin, EH, Skinner, SJ, Scales, PJ, Hawkey, A \& Kaswalder, F 2016, 'Filter press performance for fast-filtering compressible suspensions', Chemical Engineering \& Technology, vol. 39, no. 3, pp. 409-416.

Stickland, AD, Skinner, SJ, Cavalida, RG \& Scales, PJ 2017, 'Optimisation of filter design and operation for wastewater treatment sludge', Separation and Purification Technology, in press. 
